\title{
O Plano da Estratégia do TEAR_AD: Tecnologia no Ensino e Aprendizagem em Rede nas áreas de Arquitetura e Design
}

\author{
- Alice T. Cybis Pereira \\ PosDesign, PosArq, UFSC, Brasil \\ Adriele Marie Yamaguchi \\ Design, UFSC, Brasil \\ alice.cybis.pereira@ufsc.br \\ drikayamaguchi@gmail.com \\ - Luisa Eugênia dos Reis \\ Design, UFSC, Brasil \\ luisareis16@gmail.com
}

The Strategy Plan of TEAR_AD: Network for Teaching and Learning Technology in the areas of Architecture and Design

\begin{abstract}
This paper describes the beginning of a project called TEAR_AD: Network for Teaching and Learning Technology in the areas of Architecture and Design. Such project aims to support the problem of Professors, Lecturers, and students lack of knowledge about $a$ whole set of technologies that can turn a project more precise and responsive in terms of constructibility, sustainability and general performance. They have problems in keeping updated about those technologies and, in consequence, do not apply them in their practices. In order to explain the strategic plane of the project, that consists in the first part of the Garrett Methodology for Experience Design, the identification of Personas, representing the target public, the use of the benchmarking to identify possible features to be used in the system, and so on, are described. Considerations about how to pursue the implementation and maintenance of the designed system are outlined.
\end{abstract}

Keywords: Virtual Reality, Immersive Simulation, Spatial Design, Virtual Sketching, Design Instruction

\section{Introduction}

O projeto TEAR_AD (Tecnologia no Ensino e Aprendizagem em Rede nas área de Arquitetura e Design) surge devido a um contexto onde se evidencia a necessidade de suporte a professores e alunos para a incorporação das tecnologias digitais no processo de ensino e aprendizagem de projeto. Sistemas BIM (Building Information Modelling), simuladores de performance (lumínica, energética, estrutural, etc.), sistemas paramétricos e de geração de formas, prototipagem rápida/ fabricação digital são algumas tecnologias que vão muito além dos tradicionais Sistemas CAD na ajuda ao processo de projeto de forma a torná-lo cada vez mais preciso em suas proposições, evitando práticas que chegam a ser irresponsáveis perante à sociedade.

Entretanto, a complexidade dos sistemas e a falta de entendimento dos conceitos que os fundamentam, tornam a sua apropriação e aplicação no processo de ensino e aprendizagem das escolas de Arquitetura uma tarefa nada trivial. Pode-se constatar este fato nos estudos de Oliveira \& Pereira em 2011 quanto aos sistemas BIM, quando salientam que estes ainda são pouco incorporados nas práticas profissionais de Arquitetura, faltando protocolosfacilitadores para sua implementação; as pesquisas de Ruschel et al, 2013, evidenciam a forma pouco efetiva de implementação da tecnologia BIM nas escolas de Arquitetura e Eng. Civil, colocando a necessidade de incorporação de conceitos de coordenação, integração e colaboração que fundamentam o processo de BIM nas estruturas curriculares das escolas; Pupo, 2008 insiste no papel da Universidade em favorecer a difusão das técnicas de prototipagem rápida e fabricação digital no ensino de projeto; Gonçalves \& Duarte, 2007 revelam que a simulação computacional consiste em ponto crítico tanto na prática quanto no ensino de projeto, pois os softwares são complexos e existe falta de entendimento do fenômeno que representam.

Assim, evidencia-se que o processo de projeto de Arquitetura e Design tem mudado de forma muito rápida, necessitando maior integração destas tecnologias no ensino de projeto e, consequentemente, de apoio aos professores para que possam se atualizar e contribuir para uma prática de atelier mais inovadora e integrada.

Por outro lado, existe a problemática de um país extenso como o Brasil, onde a realidade dos cursos de Arquitetura e Urbanismo (AU), segundo o Ministério da Educação e Cultura (MEC) em 2011, revela a existência de 224 cursos cadastrados e distribuídos ao longo do território brasileiro; configura-se uma altíssima concentração destes na região sudeste, alta concentração na região sul, mediana nas regiões nordeste e centro-oeste e baixa concentração na região norte. Ao 
verificarmos o IGC (Índice Geral de Cursos), identificamos disparidade no grau de qualificação das Instituições de Ensino Superior (IES), principalmente da Região Norte (com índices entre 3 e 2) em relação ao restante do país (que apresentam índices entre 4 e 5). Ou seja, existe restrição de acesso à educação de qualidade reconhecida em diversas áreas do país, e este é o contexto de muitos alunos e professores de AU. A influência deste contexto afeta em muito a situação do Brasil em termos de qualidade de vida e competitividade.

Sabe-se que o Brasil já tem experiências bastante positivas com o ensino a distância. A UAB (Universidade Aberta do Brasil), que reúne universidades e centros federais em colaboração com o governo do estado e do município, fornece uma rede de pólos para apoiar o fluxo dos cursos a distância, envolvendo alunos, professores, tutores, e coordenadores. O desenvolvimento de materiais hipermidiáticos para os cursos criados promoveu a formação de grupos de design e pedagogia que adquiriram experiência no desenvolvimento de materiais de qualidade. Entre estes grupos está o Hiperlab da Universidade Federal de Santa Catarina que participou e desenvolveu inúmeros materiais didáticos de natureza hipermidiática para cursos a distância, priorizando canais visuais.

Levando em consideração os argumentos acima colocados, o grupo de pesquisa do Hiperlab propõe um projeto para a atualização de professores/alunos em relação a integração das tecnologias digitais no processo de ensino e aprendizagem de projeto de Arquitetura e Design de forma colaborativa, através de um ambiente em rede que permite a veiculação e produção de recursos de aprendizagem e, mesmo cursos, de forma livre e colaborativa, independente de localização geográfica. Este projeto chama-se TEAR_AD: Tecnologia no Ensino e Aprendizagem em Rede nas áreas de Arquitetura e Design.

\section{Metodologia}

Visando o desenvolvimento de um ambiente que aproveita as características que a Internet atual dispõe (colaboração, participação, plataformas de produção, entre outros), empregou-se a estrutura metodológica do Design da Experiência de Jesse James Garrett (2011) para o planejamento do TEAR_AD. Para o autor, todas as expectativas e possibilidades de ações do usuário devem ser previstas na construção de um ambiente web. Tal ambiente requer o conhecimento a respeito do trajeto que o usuário fará em sua interação com o sistema.

Garrett implementa em sua metodologia cinco planos ou níveis (ver Figura 1). Estes níveis funcionam como camadas de experiência do usuário, variando dos níveis mais abstratos aos mais concretos, da concepção à maturidade. Nesta sequência tem-se os seguintes níveis: estratégia, escopo, estrutura, esqueleto e superfície. A base destes níveis funciona como ponto de partida para a elaboração de um ambiente virtual, sendo a parte superficial destas camadas o que corresponde ao Design Sensorial, a saber, a consumação de um projeto web com todas as suas especificações.

Diante de um trabalho complexo e minucioso que caracteriza a elaboração de ambientes virtuais, Garrett afirma que os cinco níveis expostos em sua metodologia não são únicos, contando com outros que permeiam e promovem uma satisfatória experiência do usuário. Garrett ainda vincula nomenclaturas específicas a estes níveis, entendendo a web como interface de software e web como sistema de hipertexto. Logo, cada nível é descrito segundo estes dois entendimentos.

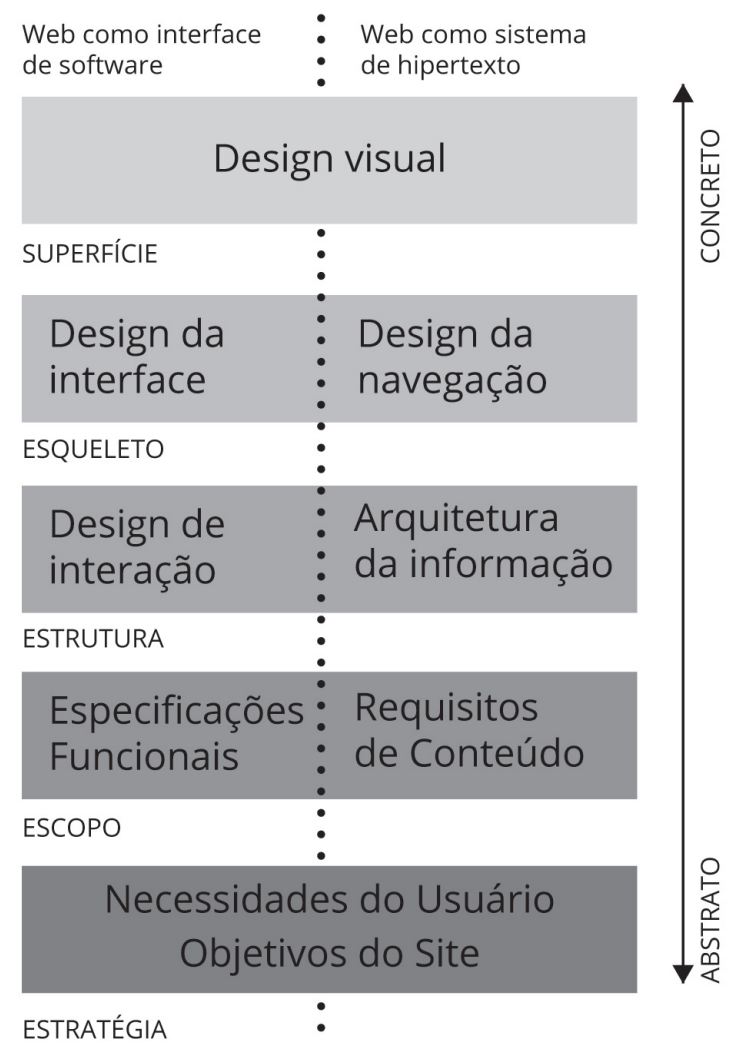

Figura 1: Imagem que explica a estrutura metodológica de Garret. Fonte: Garret (2011).

A web como interface de software é entendida como uma ferramenta que oportuniza aos usuários realizarem tarefas. Considera o trajeto do usuário no ambiente virtual, bem como as reações que advém a partir desta interação. Por outro lado, tem-se a web como sistema de hipertexto, sendo esta entendida especificamente como conteúdo informacional em um ambiente virtual, no qual os usuários podem se locomover pela informação de forma a explorá-la. Esta dualidade compreende os cinco níveis de experiência do usuário, determinando como serão compreendidos, e os objetivos projetuais.

Pelo fato de o design da interface estar concentrado no usuário e em suas experiências, faz-se necessário o emprego de estudos de usabilidade na elaboração dos ambientes 
virtuais. Segundo NIELSEN (2006) "A usabilidade é um atributo de qualidade relacionado à facilidade de uso de algo. Mais especificamente, refere-se à rapidez com que os usuários podem aprender a usar alguma coisa, a eficiência deles ao usála, o quanto lembram daquilo, seu grau de propensão a erros e o quanto gostam de utilizá-la”. A usabilidade possui elementos que transcedem a facilidade, sendo eles:

- Eficácia: Diz respeito ao cumprimento da tarefa a que o sistema se propõem; se este realiza o que o usuário espera, pode ser considerado eficaz;

- Eficiente: O sistema cumpre o que diz, permite a realização da tarefa com melhor performance e otimiza o tempo de interação do usuário. Refere-se à produtividade do sistema.

- Satisfação: O sistema proporciona um uso agradável, trazendo satisfação aos usuários.

Compreendendo as necessidades e interesses do usuário, compõe-se as estratégias, que delimitarão os objetivos para a construção do website. É necessário que estes usuários específicos estejam envolvidos no processo de concepção e estruturação do projeto, a fim de criar uma interface usável e amigável. Segundo GARRETT (2011) "O fundamento de uma experiência do usuário de sucesso é uma estratégia clara e articulada". Quanto aos objetivos, compete a compreensão do que é desejado através deste sistema, e o que os usuários anseiam através dele. Conceitos também são fundamentais para a transmissão da identidade da organização através do sistema; o usuário deverá ter alguma experiência em sua interação com este. Essa experiência do usuário fornece informações a respeito das métricas de sucesso, uma vez que apresenta estatísticas da interação do usuário com o sistema.

Os fundamentos são conhecidos através do briefing, que esclarece a finalidade do sistema e fornece instrução a respeito da organização para qual será realizado o projeto. De modo prático, o briefing envolve perguntas a respeito do que será desenvolvido, os conceitos que devem ser transmitidos, e o público alvo a ser considerado. O briefing delimita os objetos do projeto, evitando correções críticas em seu desenvolvimento.

Dentro do plano de estratégia, cabe a realização de pesquisas com os usuários, utilizando métodos quantitativos e qualitativos. As pesquisas verificam o público a ser atendido pelo produto/sistema, segmentando-o de acordo com a demanda. É importante compreender o contexto dos usuários em relação ao sistema, as tarefas que realizariam e as expectativas que possuem. Conhecendo o ambiente, comportamentos e o contexto de uso de um determinado sistema, os resultados das pesquisas possibilitam a criação de personas, que representam os usuários identificados através das pesquisas. Ainda é criado um cenário de contexto, que simula a experiência do usuário com o produto/sistema criado.

A fim de revelar as principais fontes de inspiração do sistema, é realizado um benchmarking, elencando ambientes virtuais que sejam referência ao que está em desenvolvimento. A avaliação de conteúdo e funcionalidades pode oferecer ideias interessantes que servirão como possíveis requisitos a um projeto. São então levantados os requisitos do sistema, dizendo respeito ao que este deve ter. Envolve a avaliação dos objetivos do sistema e dos usuários, de forma a organizar e determinar o grau de importância de cada item.

Estes prévios estágios concedem ao projeto um compilado minucioso para a definição do plano de escopo. Este abriga de modo mais teórico as características do sistema, que serão consumadas de forma pragmática nas fases posteriores do projeto. O Plano de Escopo é de suma importância para o estabelecimento dos conteúdos do ambiente, e de que forma suprirão as necessidades dos usuários. Nesta fase essencial o que ainda está na em forma abstrata sofre lapidações, a fim de rever questões importantes e excluir o que não é interessante. Isto clarifica e viabiliza o desenvolvimento do projeto, uma vez que permite o conhecimento daquilo o que deve ser realizado. A partir destes primeiros planos tem-se condições de gradativamente ir desenvolvendo os outros três planos (estrutura, esqueleto e superfície) para se chegar ao projeto completo do sistema que busca proporcionar uma boa experiência do usuário.

Neste artigo será exposto os resultados do primeiro e mais abstrato dos planos: o plano da estratégia, que prevê a identificação das necessidades do usuário e dos objetivos do site. Pesquisas exploratórias, questionários e grupo focal foram as técnicas utilizadas para o desenvolvimento deste plano.

\section{Resultados}

Como ponto de partida do Plano de Estratégia, e do projeto em seu contexto geral, foi realizado o briefing, que esclareceu a consistência a respeito do sistema a ser desenvolvido. Este projeto é articulado com algumas instituições de ensino superior, a saber, Universidade Federal de Pelotas (UFPEL), Universidade Comunitária da Região de Chapecó (Unochapecó), Universidade do Estado de Santa Catarina (UDESC) e Universidade Federal de Santa Catarina (UFSC). Desta última sobreveio a concepção do projeto, bem como a identificação da demanda e da problemática. Tal concepção e instituição de grupo focal foi estabelecida a partir do HiperLab, Laboratório de Ambientes Hipermidia de Aprendizagem que articula suas atividades juntamente com o Departamento de Expressão Gráfica, do Centro de Comunicação e Expressão da UFSC. Formou-se então um grupo focal, formado por professores, doutorandos, mestrandos e bolsistas.

Determinou-se que o ambiente a ser desenvolvido objetiva fomentar a tecnologia junto aos alunos $e$ profissionais da Arquitetura e do Design, encarando isso como uma questão de responsabilidade social na formação destas áreas de conhecimento. $\mathrm{O}$ ambiente ainda objetiva conscientizar os professores a respeito da importância do ensino e aprendizagem situada das tecnologias que envolvem o saber e a prática de projeto. Desta forma, o professor terá sugestões de como os alunos poderão utilizar os materiais disponibilizados pelo sistema, prestando auxílio para uma análise superior e aprofundada. 
O sistema disponibilizará materiais selecionados ou produzidos, a saber, materiais midiáticos, cursos estruturadose recursos de aprendizagem, ficando disponíveis na biblioteca do sistema. Esta proposta visa a geração de materiais para ensino, pesquisa e extensão. Os professores usarão na graduação. Os alunos da pós-graduação analisarão, pesquisarão e gerarão coisas novas, e alimentarão de novo o ambiente. Há também a aplicação na comunidade, como um elemento de extensão, onde profissionais que precisam de atualização e capacitação entrarão em contato com os materiais. Ademais, a proposta do TEAR_AD é de ser uma comunidade colaborativa, sendo uma área de compartilhamento de experiências. Isto pode ser observado a partir da criação de um espaço destinado a um sistema de Hiperlivro, orientado a criações coletivas, compilando e gerando materiais instrucionais selecionados.

Através da realizaçãode um grupo focal com a participação de professores, alunos de pós-graduação e graduação de arquitetura e Design, assim como arquitetos, designers e programadores, conseguiu-se evidenciar os conceitos do DNA do projeto. Estes conceitos são: Especialista; Parceiro; Fomentador Tecnológico; Engrandecedor; Inspirador. A seguinte imagem perceptiva do sistema foi originada: "O TEAR_AD é um especialista em fomentar tecnologias, de maneira a engrandecer o aprendizado e a inspirar para criar coisas novas; é um parceiro com quem se pode contar diante de novos desafios".

Identificando o problema e a demanda, foram realizadas pesquisas com o público-alvo. A amostra deteve-se em dois nichos específicos, a saber, alunos e professores oriundos dos cursos de Arquitetura e Urbanismo da UFSC e da Unochapecó. As pesquisas tiveram caráter quantitativo, a fim de determinar um comportamento em questão. Em relação aos alunos, as entrevistas contaram com a amostra total de 30 pessoas, das duas universidades especificadas.

A pesquisa com os alunos forneceu a compreensão de que o nicho se caracteriza como massivo utilizador da internet (sendo que 93\% utiliza todos os dias, com 53\% utilizando durante 4 hs ou menos, 33\% de 5 a 9 horas e 13\% mais que 10 horas por dia), com finalidades de navegação equilibradas entre Pesquisa (24\%), Estudo (24\%), Lazer (24\%) e Comunicação (26\%). Os dispositivos mais utilizados são os Notebooks (60\%) e Smartphones (26\%). No que se refere aos professores, a pesquisa teve uma amostra total de 5 pessoas atuantes na Universidade Federal de Santa Catarina. Embora não seja representativa, esta pesquisa traz um indício de como é o perfil dos professores.

Conclui-se que o contexto de uso da internet e de dispositivos que permitem interação digital tendem a ser amplamente usados pelos professores. Tendem a utilizar a Internet todos os dias, sendo a maioria durante 4 hs ou menos (60\%), ficando dividido o restante entre 5 a 9 horas (20\%) e mais de 10 horas diárias (20\%). A finalidade de uso concentrase mais na Pesquisa (37\%), Trabalho (25\%), Comunicação (25\%) e por último Lazer (12\%). Ao contrário dos alunos, o grupo de professores tende a utilizar mais Computadores de mesa (30\%) e Tablet (30\%), ficando Notebook (23\%) e Smartphone (15\%) com menor utilização.

A partir deste contexto, confirma-se a relevância que um ambiente virtual de aprendizagem teria no cotidiano de tais pessoas, uma vez que estas têm amplitude de uso de seus dispositivos, e o fazem para finalidades diversas conforme apresentadas na pesquisa, sendo a de pesquisa bastante relevante.

Diante da síntese de tais entrevistas, e do conhecimento do público-alvo, são criadas personas, sendo estas personagens fictícias criados para representar os diferentes tipos de usuário dentro de alvo demográfico. A criação destas personas permite ter, de forma mais objetiva, o conhecimento das necessidades/ objetivos destes usuários, definindo o comportamento que o produto deve ter. O resultado forneceu três personas:

Um professor Doutor de Arquitetura e Urbanismo de meia-idade, cuja frase característica seria "Procuro fazer meu trabalho com excelência e ser alguém relevante na formação de novos profissionais; por isso estou sempre buscando por conteúdos atualizados e confiáveis para aplicá-los na pesquisa e na preparação de minhas aulas".

Um Professor doutor, no entanto mais idoso e menos contextualizado com as novas tecnologias, que falaria "A tecnologia voa... São muitas transformações em curtos períodos de tempo. Acompanhar tudo isso é uma tarefa deveras desafiadora".

Uma jovem estudante de Arquitetura e Urbanismo que diria "Eu queria poder usar o pouco de tempo que tenho para aprender a usar novas tecnologias de uma maneira fácil e simples".

Nos cenários de contexto, as personas em questão são apresentadas em sua interação com o sistema, num contexto de seus cotidianos. A aluna de arquitetura é retratada em seu anseio por otimizar o seu tempo aprendendo o uso de tecnologias de uma maneira facilitada. Através de seus professores, entra em contato com o sistema e surpreendese pelos materiais que pode utilizar para desenvolver sua performance tecnológica, situando isto aos projetos que lhe são propostos. O professor de mais idade que possui dificuldade em acompanhar as transformações tecnológicas em sua área, vislumbra o sistema através de seu neto, graduando de curso de Arquitetura e entusiasta da metodologia BIM. Olavo foi encorajado a utilizar o site e orientar-se a partir das instruções ali explanadas, e verificou que o modo de ensino facilitava consideravelmente a compreensão dos temas, adotando o sistema como um útil suporte às suas aulas e ao seu próprio desempenho profissional. No que diz respeito ao outro professor, tem-se um cenário de contexto no qual este é apresentado ao sistema através da indicação do Departamento onde leciona. Animou-se com a questão da colaboratividade proporcionada pelo ambiente, encontrando ótimos complementos para a preparação de suas aulas. Desta forma, o professor obteve maior desempenho na preparação de suas aulas, e passou a utilizar o sistema para realizar novas pesquisas, além de manter-se constantemente atualizado com 
os conteúdos selecionados no TEAR_AD.

Os cenários de contexto viabilizaram a pragmatização de requisitos que deveriam ser apropriados ao sistema, levando em conta as interações e desejos previstos nas etapas antecedentes.

O Benchmarking revelou as principais fontes de inspiração do sistema, evidenciando-se referencias de interação, de conteúdo e gráficas. Para isto, foram elencados sites que provessem inspirações nos quesitos citados anteriormente. Foi realizada uma completa navegação em cada um dos ambientes indicados pelos pesquisados e também pelos próprios pesquisadores envolvidos. Após análise dos sites foram lançadas notas referentes aos conceitos do TEAR_AD na tabela 1. Estas notas demonstrariam o quanto determinado site elencado no benchmarking representa um respectivo conceito, sendo 0 (zero) como nada representado, e 5 (cinco) como que representando muito o conceito.

\begin{tabular}{|l|c|c|c|c|c|}
\hline SITE/CONCEITo & Tecnológico & Inspirador & Especialista & $\begin{array}{l}\text { Fomentador } \\
\text { De Tecnologia }\end{array}$ & Parceiro \\
\hline Archi Graphi & 5 & 4 & 3 & 5 & 1 \\
\hline Formica Envisualizer & 3 & 4 & 4 & 3 & 3 \\
\hline Devart with Google & 5 & 5 & 5 & 5 & 3 \\
\hline SciencesPo & 3 & 4 & 3 & 3 & 5 \\
\hline Skillshare & 3 & 4 & 3 & 3 & 4 \\
\hline
\end{tabular}

Figura 2: Síntese de sites e conceitos resultantes do Benchmarking. Fonte (elaborada pelas autoras).

\begin{tabular}{|l|l|}
\hline OBJETIVOS & Requisitos de Conteúdo \\
\hline $\begin{array}{l}\text { Engajar o aluno e } \\
\text { professores a aprender; }\end{array}$ & $\begin{array}{l}\text { Fracionar as informações em pequenas porções; } \\
\text { Apresentar os benefícios adquiridos através da } \\
\text { apreensão de novas tecnologias; } \\
\text { Disponibilizar cursos e recursos de Aprendizagem } \\
\text { orientados ao ensino e aprendizagem de tecnologia } \\
\text { de forma situada. }\end{array}$ \\
\hline $\begin{array}{l}\text { Ensinar novas tecnologias } \\
\text { de forma amistosa; }\end{array}$ & $\begin{array}{l}\text { Prover suporte compartilhado através de uma } \\
\text { comunidade de prática; } \\
\text { Transmitir os tutoriais e demais conteúdos de } \\
\text { maneira amistosa e envolvente, utilizando uma } \\
\text { linguagem confiável e descontraída. }\end{array}$ \\
\hline Criar Networking & $\begin{array}{l}\text { Disponibilizar espaço com informações pessoais } \\
\text { e profissionais; } \\
\text { Prover espaço para publicação de projetos } \\
\text { realizados com as tecnologias ensinadas; } \\
\text { Disponibilizar espaço de comunicação. }\end{array}$ \\
\hline $\begin{array}{l}\text { Dino/ aprendizagem; } \\
\text { Otimizar do tempo dedicado a preparação de aulas; } \\
\text { Aprendizagem; } \\
\text { Fomentar produções coletivas; } \\
\text { Possibilitar o oferecimento de materiais com } \\
\text { objetivos informacionais semelhantes. }\end{array}$ \\
\hline
\end{tabular}

Figura 3: Síntese das estratégias traçadas. Fonte (elaborada pelas autoras).
De forma a atender ao público-alvo, representado pelas personas, e baseando-se nas possibilidades evidenciadas pelo benchmarking, traçou-se as seguintes estratégias para o TEAR_AD.

Em relação à abordagem pedagógica/andragógica, o TEAR_AD segue as diretrizes da Cognição Situada onde "as pessoas aprendem ao participar de comunidades de prática permitindo progredir em sua experiência pela observação, reflexão, mentoria e legitima participação periférica"(Filatro, 2008, p.15). A aprendizagem acontece pela semelhança e a aplicabilidade da situação e contexto, fazendo com que a autenticidade destes seja significativa ao aprendiz. Filatro coloca as implicações para o ensino que também servem para orientar o desenvolvimento do sistema desejado: segurança para a participação; meios de desenvolvimento de identidades; meios para facilitar diálogos e relacionamentos de aprendizagem; elaboração ou disponibilização de conteúdos de aprendizagem autênticas.

\section{Discussão}

O desenvolvimento do plano da estratégia mostrou a complexidade em achar as bases de desenvolvimento de um projeto que pretende permitir a seus usuários uma experiência de conhecimento, engajamento e divulgação. Sem a colaboração do grupo focal composto de arquitetos, designers, programadores, professores e estudantes, não seria possível chegar aos resultados apresentados, pois as diferentes visões trouxeram a riqueza de ideias para a discussão. A pesquisa com professores mostrou-se de difícil viabilização, necessitando dedicação singular a fim de captar e compreender este contexto específico.

Um projeto desta escala revela a importância de um método bem estruturado, neste caso o de Garrett, para orientar $\mathrm{o}$ seu desenvolvimento. $O$ plano da estratégia consiste no primeiro plano do método que fornece o eixo para a continuidade dos outros planos.

O desenvolvimento e aplicação de ambientes virtuais de aprendizagem atuam num momento muito propício devido às tecnologias articuladas no grande âmbito Web. Desde o advento da internet na década de 90 , aperfeiçoamentos baseados no perfil de usuários tem ocorrido muito rapidamente. Os saltos de aprimoramento se dão em tempo efêmero, o que torna complexa a nomeação dos acontecimentos vigentes. $O$ que antes era estático e de pouca interatividade com a Web 1.0, tornouse em meados de 2004 algo mais participativo com a Web 2.0, através do compartilhamento e modificações informacionais realizadas pelos próprios usuários. Desde 2007, tem-se o desenvolvimento da Web 3.0, a saber, a Web semântica, que se aproxima da inteligência artificial, que permite a criação de sistemas de conhecimento coletivo. Isto é possível graças à tecnologia de decifração de dados, fruto de otimizações das linguagens de programação 
para que haja similaridade na comunicação entre homem e máquina, permitindo à Web 3.0 conectar informações já disponíveis na rede.

É interessante perceber o momento propício para a criação de um ambiente com as características previstas no plano de estratégia do TEAR_AD, uma vez que a tecnologia que hoje articula a Web 2.0 passa a evoluir para o contexto da Web 3.0, que permite a criação de sistemas de conhecimento coletivo. Esta inovadora característica abrange a proposta do ambiente em questão no que se refere ao compartilhamento informacional oriundo dos usuários. Através deste sistema inteligente, os usuários desfrutarão de orientações sugestivas a respeito de conteúdos pertinentes. A questão da colaboratividade torna-se viável, uma vez que esta nova possibilidade interativa tem seu apogeu no tempo presente, o que corrobora a produção de conhecimento coletivo mediada pela contribuição colaborativa humana. Tal fato permite a geração e reutilização de conhecimento, tornando viável a outras pessoas a criação de conteúdo.

Como forma de viabilizar este ambiente que suportará o TEAR_AD dentro de uma problemática de educação tecnológica em Arquitetura e Design, traça-se um plano de implementação e manutenção baseado nos fundamentos da Rede. O compartilhamento de materiais e experiências, a criação colaborativa de recursos educacionais, o reconhecimento de especialidades de grupos e desenvolvimento de novas relações em torno de temas tecnológicos necessários para a viabilização de uma mudança qualitativa no ensino de arquitetura e design, contribuirão para o sucesso e manutenção deste projeto.

Conta-se, neste início, com o apoio do CNPq e da UFSC através de recursos humanos e financeiros. Na continuidade aposta-se no compartilhamento de recursos pela própria comunidade de prática que se formará, podendo-se ter apoio das entidades de classe e de empresas que fornecem as tecnologias.

\section{Agradecimentos}

Agradecimento ao $\mathrm{CNPq}$ (Conselho Nacional de Desenvolvimento Científico e Tecnológico) e a UFSC (Universidade Federal de Santa Catarina).

\section{Referências}

GARRETT, Jesse James. The Elements of User Experience: User-Centered Design for the Web and Beyond, Second Edition. Berkeley: New Riders, 2011.

GONÇALVES, Joana Carla Soares \& DUARTE, Denise Helena Silva. Arquitetura sustentável: uma integração entre ambiente, projeto e tecnologia em experiências de pesquisa, prática e ensino. In Ambiente Construído, v. 6, n. 4, 2006.

OLIVEIRA, Ludmila Cabizuca ; PEREIRA, Alice Theresinha Cybis . MUDANÇAS METODOLÓGICAS DECORRENTES DA IMPLANTAÇÃO RECENTE DE BIM EM ESCRITÓRIOS DE ARQUITETURA. In: XV SIGRADI - Congresso de la Sociedad Iberoamericana de Gráfica Digital, 2011, Santa Fé - Argentina. SIGRADI 2011 - Cultura Aumentada., 2011. v. XV. p. 134-137. PUPO, R. T. . Ensino da prototipagem rápida e fabricação digital para arquitetura e construção no Brasil: definições e estado da arte. PARC, v. 1, p. 1-19, 2008.

RUSCHEL, Regina Coeli, de ANDRADE, Max Lira Veras Xavier; de MORAIS, Marcelo. O ensino de BIM no Brasil: onde estamos? In Ambiente Construído, v. 13, n.2. 2013.

FILATRO, Andrea. Design Instrucional na prática. São Paulo, Pearson Education do Brasil, 2008.

Ministério da Educação e Cultura (MEC) em 2011

Portal de EAD (http://www.ead.com.br/cursos-distanciadesempenho-enade/).

ISOTANI Seiji; MOZOGUCHI Riichiro; BITTENCOURT Ig Ibert; COSTA Evandro. WEB 3.0 - OS RUMOS DA WEB SEMÃNTICA E DA WEB 2.0 NOS AMBIENTES EDUCACIONAIS. iN: XIX Simpósio Brasileiro de Informática na Educação, 2008, Fortaleza, CE - Brasil. SBIE 2008 - "Tecnologia e Educação para todos". Disponível em: http://www.br-ie.org/pub/index.php/ sbie/article/view/767 